\title{
GOVERNANÇA CORPORATIVA: NÍVEL DE EVIDENCIAÇÃO \\ DAS INFORMAÇÕES E SUA RELAÇÃO COM A VOLATILIDADE \\ DAS AÇÕES DO IBOVESPA
}

\section{CORPORATE GOVERNANCE: INFORMATION DISCLOSURE LEVEL AND ITS RELATION WITH THE STOCK PRICE VOLATILITY ON IBOVESPA}

\author{
MARA JANE CONTRERA MALACRIDA \\ Doutoranda em Controladoria e Contabilidade na \\ Faculdade de Economia, Administração e Contabilidade da \\ Universidade de São Paulo - Campus Capital \\ E-mail: maracontrera@uol.com.br \\ MARINA MITIYO YAMAMOTO \\ Professora Associada do Departamento de Contabilidade e Atuária \\ da Faculdade de Economia, Administração e Contabilidade da \\ Universidade de São Paulo - Campus Capital \\ E-mail:marinamy@usp.br
}

\section{RESUMO}

Este estudo busca analisar se o nível de evidenciação de informações contábeis, apresentadas pelas empresas componentes do Ibovespa, influencia a volatilidade do retorno de suas ações quando negociadas na Bolsa de Valores de São Paulo, pois se espera que empresas com maior nível de evidenciação apresentem menor volatilidade dos retornos de suas ações. Para efetuar a análise entre o nível de evidenciação e a volatilidade do retorno das ações, fez-se necessária a coleta das informações publicadas por 42 empresas pertencentes ao Ibovespa, através dos relatórios anuais referentes ao exercício de 2002. Após segregar essas companhias em 3 grupos distintos, de acordo com seus níveis específicos de evidenciação, foram aplicados testes estatísticos com o propósito de se verificar a existência de diferenças significativas entre o nível de evidenciação das empresas e a volatilidade do retorno das suas ações. Este estudo caracteriza-se como empírico-analítico, e as análises possibilitaram a constatação de que as empresas com maior nível médio de evidenciação das informações contábeis apresentam menor volatilidade média dos retornos das ações; as empresas com menor nível médio de evidenciação das informações contábeis apresentam maior volatilidade média dos retornos das ações. Com isso, verifica-se que maior nível médio de evidenciação resulta em menor volatilidade média dos retornos das ações.

Palavras-chave: Governança Corporativa; Evidenciação; Transparência; Ações.

\section{ABSTRACT}

This empirical-analytical study investigates the role of accounting as a source of information to the Brazilian capital market. It aims to verify whether the accounting disclosure level provided by Brazilian entities is related to the volatility of their share prices on Bovespa (Brazilian Stock Exchange). Entities with greater accounting disclosure level are expected to present lower volatility of their stock returns. To analyze the relation between disclosure level and stock price volatility, we collected information published by 42 companies listed on Ibovespa, using the annual reports for 2002. After segregating these companies into three different groups in accordance with their specific disclosure level, using cluster analysis, we statistically verified the existence or not of significant differences between their disclosure and stock price volatility levels. The analyses indicated that the companies with better average accounting disclosure presented lower mean volatility levels, while the cluster with worse average disclosure presented higher mean volatility levels. This evidences that higher average disclosure levels result in lower mean volatility of stock returns.

Keywords: Corporate governance; Disclosure; Transparency; Stock. 


\section{INTRODUÇÃO}

A divulgação de informações, por parte das empresas, é fundamental para os seus usuários no processo de tomada de decisões. Assim, a evidenciação clara, objetiva e completa possibilita um maior grau de confiabilidade e segurança ao se decidir por uma alternativa em detrimento de outras.

Atualmente, existem várias normatizações (leis, pareceres, instruções) que tornam a divulgação de várias informações econômico-financeiras obrigatórias para as companhias abertas. No entanto, há outras, cuja divulgação é de caráter voluntário e depende de fatores independentes da imposição legal, tais como conscientização da necessidade e respeito.

O argumento utilizado para que haja um maior nível de evidenciação por parte das empresas, independentemente da obrigatoriedade, é a esperada repercussão positiva dessas informações no Mercado de Valores Mobiliários, contribuindo para uma melhor avaliação financeira da empresa; entre outras repercussões positivas, citam-se: maior retorno, menor custo de captação e menor flutuação de seus preços de mercado.

Considerando os aspectos citados, este estudo investiga, empiricamente, a importância das informações contábeis para o mercado de capitais brasileiro, buscando analisar o nível de evidenciação dessas informações nas empresas componentes do Índice Bovespa (índice que mede o desempenho da Bolsa de Valores de São Paulo, diariamente, baseado em um conjunto de empresas), com a finalidade de responder à seguinte questão da pesquisa

O nível de evidenciação das informações econômico-financeiras tem relação com a volatilidade do retorno das ações das empresas que compõem o Índice Bovespa?

Uma vez formulado o problema, é proposta uma provável resposta provisória (hipótese), para a sua solução. Nesse caso, após verificar o problema de pesquisa, tem-se a Hipótese Metodológica: $A$ volatilidade do retorno das ações das empresas independe do nível de evidenciação.

Para responder ao problema da pesquisa e testar a hipótese formulada, foram coletadas informações publicadas por 42 empresas pertencentes ao Ibovespa, através dos relatórios anuais referentes ao exercício de 2002. Após segregar essas companhias em 3 grupos distintos, de acordo com seus níveis específicos de evidenciação, foram aplicados testes estatísticos com o propósito de verificarse a existência de diferenças significativas entre o nível de evidenciação das empresas e a volatilidade do retorno das suas ações.

Utilizou-se o conjunto de normas legais relativas à divulgação de informações, comparando as divulgações efetivas das empresas com as obrigatórias. Para as informações voluntárias foram consideradas as informações relevantes publicadas ou não.

Para o cálculo da volatilidade dos retornos das ações utilizou-se o desvio-padrão desses retornos.

Este artigo traz importantes contribuições para a pesquisa em contabilidade, uma vez que não só analisa as informações requeridas para divulgação pelos órgãos normativos, como também as informações complementares (voluntárias) e as relaciona com o comportamento das ações no mercado de capitais brasileiro, tratando-se de uma abordagem inédita no Brasil.

A utilização da análise de cluster para o tratamento da base empírica constitui contribuição para que esse instrumento possa ser mais explorado em pesquisas contábeis.

Desse modo, este estudo justifica-se pela necessidade de constatar, através de pesquisa empírica, se o nível de evidenciação impacta na volatilidade do retorno das ações negociadas na Bovespa, ou seja, se a evidenciação é importante para a diminuição do risco apresentado pelas empresas.

Este estudo caracteriza-se como empírico-analítico, pois está voltado para a pesquisa aplicada na qual há tratamento quantitativo dos dados obtidos, buscando uma relação causal entre as variáveis objeto do estudo. A partir da pesquisa bibliográfica, buscou-se obter fundamentação conceitual para a realização e interpretação dos resultados. $A$ análise descritiva foi utilizada para a interpretação e análise do nível de evidenciação das empresas. A análise quantitativa baseou-se em testes estatísticos para a avaliação final dos resultados.

No decorrer do trabalho, são apresentados os aspectos teóricos envolvidos e a análise dos dados que fundamentam a sua conclusão.

\section{OBJETIVOS DA CONTABILIDADE E EVIDENCIAÇÃO}

De acordo com ludícibus (2000, p. 28),

O objetivo principal da Contabilidade (e dos relatórios dela emanados) é fornecer informação econômica relevante para que cada usuário possa tomar suas decisões e realizar seus julgamentos com segurança.

ludícibus ressalta, assim, a importância da evidenciação das informações contábeis, pois, através desse meio de co- municação, a contabilidade consegue atingir seu objetivo principal. Dessa forma, todos os eventos, que afetem, ou que possam vir a afetar, a situação patrimonial, econômica e financeira de uma dada entidade, devem ser evidenciados.

Para o International Accounting Standards Board (IASB, 200 I, p. 46), o objetivo das demonstrações contábeis é fornecer informações sobre a posição financeira, os resultados e as mudanças na posição financeira de uma 
entidade, que sejam úteis a um grande número de usuários em suas tomadas de decisão.

Dessa maneira, pode-se considerar como objetivo central da contabilidade o fornecimento de informações úteis aos seus usuários, no intuito de que possam tomar decisões adequadas, pois é através do processo de evidenciação que a contabilidade busca atender a seus usuários, à medida que os fatos econômicos relevantes são divulgados de forma adequada, justa e plena, seguindo procedimentos contábeis uniformes e consistentes e em uma linguagem simples e que lhes seja acessível.

Quanto à definição da quantidade e tipos de informações a serem divulgadas, existem 3 conceitos bastante utilizados: evidenciação adequada (adequate disclosure), evidenciação justa (fair disclosure) e evidenciação plena (full disclosure). No entanto, para ludícibus (2000, p. I I 7):

[...] não existe diferença efetiva entre tais conceitos [...] toda informação para o usuário precisa ser, ao mesmo tempo, adequada, justa e plena, pelo menos no que se refere ao detalhe que está sendo evidenciado. Afinal, o sentido da evidenciação é que a informação que não for relevante deve ser omitida.

Outra discussão se refere aos benefícios que a empresa pode obter em função de uma melhor evidenciação. Há um consenso, entre profissionais e acadêmicos, de que uma melhor evidenciação pode trazer benefícios para a empresa. Nesse sentido, foi realizada uma pesquisa pela PricewaterhouseCoopers. De acordo com Eccles et al. (200I, p. 189), ela se refere a uma pesquisa de opinião realizada entre investidores institucionais e analistas.

De acordo com tal pesquisa, cinco pontos são citados como sendo os maiores benefícios de uma melhor evidenciação: aumento da credibilidade dos gestores; mais investidores de longo prazo; maior monitoramento por parte dos analistas; melhor acesso a novos capitais e melhor avaliação do preço das ações.

Em relação ao primeiro benefício, Eccles et al. (200 I, p. 192) comentam que, fornecendo consistentemente informação em ambos os momentos, bons e ruins, a gerência reafirma a sua credibilidade com o mercado. O mercado odeia surpresas, especialmente as negativas. Entretanto, conforme os mesmos autores (200 l, p. 193):

[...] Isso não significa que uma má notícia não terá um efeito negativo no preço das ações da companhia. Provavelmente terá, e provavelmente deveria ter se a notícia é suficientemente ruim, e os indicadores principais também são negativos. Mas, quando esses indicadores tornam-se positivos, o preço das ações da companhia também terá maior probabilidade de ascensão.

Quanto ao segundo benefício, Eccles et al. (200l, p. 194) complementam que, por existirem investidores que decidem aumentar os seus investimentos e também novos investidores de longo prazo, ambos os grupos necessitam de informação que lhes trará um maior conforto em realizar esses compromissos de longo prazo.

De acordo com os autores (200l, p. 196), o terceiro benefício diz respeito a um maior monitoramento por parte dos analistas, sendo que:

[...] um dos melhores caminhos para atrair a atenção do mercado é provê-lo com muita informação. Isso concede tanto a analistas quanto a investidores algo para analisar de modo que eles possam determinar se uma oportunidade de investimento existe.

O quarto benefício de uma melhor evidenciação está relacionado ao custo de capital, ou seja, a empresa detentora de maior acesso a novos capitais tem mais oportunidades de obter um menor custo de capital. Contudo, conforme Botosan (1997, p. 323), “a associação entre o nível de evidenciação e o custo do capital próprio não está bem estabelecida e tem sido difícil de quantificar."

O quinto benefício, segundo Eccles et al. (200l, p. 198), está relacionado aos demais benefícios, sendo que:

[...] Os quatro primeiros benefícios de uma melhor evidenciação - aumento da credibilidade dos gestores, mais investidores de longo prazo, maior monitoramento por parte dos analistas e melhor acesso a novos capitais - logicamente contribuem para aumentar o preço de ação.

Ressalte-se, ainda, de acordo com tais autores (200I, p. 188), que

um argumento para a melhoria da evidenciação é que os gestores tipicamente pensam em estar fazendo um trabalho de comunicação com o mercado melhor do que o mercado pensa que eles fazem.

Assim, os dirigentes supõem ter uma boa comunicação com o mercado, cuja visão, contudo, não é essa. Nesse sentido, os mesmos autores ainda (200 I , p. 189) afirmam que

a maioria dos gestores genuinamente acredita em seu grande esforço para dar ao mercado a informação desejada. Mas a maioria dos analistas e investidores acredita em que os gestores poderiam se esforçar mais.

No entanto, os autores (200 I , p. 189) destacam o fato de que:

Por hora, ler 'melhor evidenciação' como simplesmente 'mais evidenciação', significa dar ao mercado mais da informação que ele considera importante e menos da que ele não considera. É bom ter em mente, contudo, que um mero aumento de quantidade não necessariamente aumentará a qualidade da informação.

Embora essa questão seja relacionada a uma das maiores dificuldades concernentes a esse assunto, a identificação de pontos realmente referentes ao aumento de quantidade e não de qualidade é de difícil segregação. 


\section{GOVERNANÇA CORPORATIVA}

A evolução constante das sociedades capitalistas traz uma nova relação entre as empresas e a sociedade como um todo e, em muitos casos, essa evolução culmina na segregação entre os proprietários das companhias e seus administradores. Essa segregação entre controle e gestão pode provocar conflitos de interesses entre acionistas, investidores e demais interessados na empresa.

Nesse contexto de mudanças, surge a Governança Corporativa como um processo para reduzir a distância existente entre proprietários e administração da empresa e a sociedade de maneira geral. Desse modo, de acordo com Siffert Filho (1998, p. 125),

as questões de governança corporativa ganharam maior relevância a partir do surgimento das modernas corporações, nas quais há separação entre controle e gestão.

Shleifer e Vishny (1997, p. 737) definem governança corporativa como um conjunto de mecanismos pelos quais os fornecedores de recursos garantem a obtenção para si do retorno sobre seu investimento.

Para a Organization for Economic Co-operation and Development (OECD, 2004a) governança corporativa envolve:

[...] Um conjunto de relacionamentos entre a gerência da companhia, seus boards, acionistas, e outros stakeholders. Governança corporativa também fornece a estrutura pela qual os objetivos da companhia são estabelecidos, e os meios para atingi-los e monitoramento da performance são determinados.

Para a Comissão de Valores Mobiliários (CVM, 2002), governança corporativa é

o conjunto de práticas que tem por finalidade otimizar o desempenho de uma companhia ao proteger todas as partes interessadas, tais como investidores, empregados e credores, facilitando o acesso ao capital.

\section{De acordo com o IBGC (2004a):}

$\mathrm{Na}$ teoria econômica tradicional, a governança corporativa surge para procurar superar o chamado 'conflito de agência', presente a partir do fenômeno da separação entre a propriedade e a gestão empresarial. O "principal", titular da propriedade, delega ao "agente" o poder de decisão sobre essa propriedade. A partir daí surgem os chamados conflitos de agência, pois os interesses daquele que administra a propriedade nem sempre estão alinhados com os de seu titular. Sob a perspectiva da teoria da agência, a preocupação maior é criar mecanismos eficientes (sistemas de monitoramento e incentivos) para garantir que o comportamen- to dos executivos esteja alinhado com o interesse dos acionistas.

Desse modo, percebe-se que a governança corporativa surgiu para criar mecanismos que permitam controlar e monitorar os negócios, não somente pelos gestores internos, mas também pelos acionistas, possibilitando identificar e solucionar prováveis conflitos de agência a surgirem dentro de uma organização.

Segundo Lopes (2001, p. 123), o papel da contabilidade tem sido reconhecido desde os primeiros estudos em governança corporativa, sendo fundamental tanto para o estabelecimento de contratos entre os agentes quanto para o papel de redutora da assimetria informacional. Corroborando esse entendimento, Tirole (200 I , p. I) expõe que:

[...] Atualmente, é conhecido que os gestores, por assim dizer, podem realizar ações que podem prejudicar os acionistas. Eles não se esforçam o suficiente quando se dedicam em demasia a atividades externas, quando acham conveniente aceitar um excesso de hierarquização, ou quando fazem vista grossa aos controles internos. Eles podem obter benefícios pessoais com a construção de impérios, empertigarem-se por deleite pessoal ou até desviarem recursos da firma por meio da manipulação dos fundos de pensão, com o pagamento de preços de transferência inflados a partes relacionadas ou com o exercício de insider trading.

A governança corporativa utiliza os principais conceitos relacionados à Contabilidade, tais como: transparência (disclosure), eqüidade, prestação de contas (accountability) e responsabilidade corporativa (sustentabilidade) para explicar e solucionar os conflitos existentes entre os interesses dos stakeholders. Dessa forma, a contabilidade interage com a governança corporativa na tentativa de indicar caminhos, não apenas em relação às questões concernentes aos controles internos como também à prestação de contas, a qual envolve, entre outras, a divulgação das informações a todos os interessados (eqüidade). Por outro lado, os modelos de governança corporativa requerem novas abordagens para soluções de problemas, representando desafios e oportunidades para a contabilidade.

De acordo com Yamamoto (2004):

A governança corporativa, como técnica ou sistema de estruturação societária, não deve ser vista apenas sob a ótica da otimização da relação retorno-risco ou como meio de captar recursos no mercado a custo mais baixo. Isso seria uma visão muito pobre. Deve, sim, ser vista como um valor a ser incorporado às práti-

I Para maiores esclarecimentos sobre conflito de agência vide Silveira (2002) e Jensen (1988, p. 2 I-48).

2 Entende-se por boa governança corporativa um conjunto de práticas e mecanismos o qual proporciona aos proprietários (acionistas ou cotistas) a gestão estratégica de sua empresa e a efetiva monitoração da direção executiva, protegendo todas as partes interessadas contra desvios de ativos por indivíduos com poder de influenciar ou tomar decisões em nome da empresa. 
cas empresariais, independentemente do ganho fortuito que possa proporcionar.

Para a OECD (apud THOMSON, 2003, p I0), a empresa com uma boa governança², na área de mercado de capitais, observa os seguintes princípios:

1) Reconhece e protege os direitos dos acionistas;

2) Trata todos os acionistas eqüitativamente, incluindo os minoritários e estrangeiros;

3) Adota processos e procedimentos para corrigir as violações desses direitos;

4) Proíbe a negociação de ações com base em informações privilegiadas;

5) Reconhece e protege os direitos de outras partes interessadas;

6) Desenvolve mecanismos de informação para que todas as partes interessadas participem do processo de governança.

No Brasil, entre as principais iniciativas de estímulo e aperfeiçoamento do modelo de governança corporativa das empresas destacam-se: a criação do Novo Mercado pela Bolsa de Valores de São Paulo, as linhas de crédito especiais oferecidas pelo BNDES, as novas regras de investimento por parte de fundos de pensão e o projeto de reforma das demonstrações contábeis.

Além do Novo Mercado, foram criados os chamados "Níveis Diferenciados de Governança Corporativa" da Bovespa, com a finalidade de incentivar e preparar, gradativamente, as companhias para aderirem ao Novo Mercado, proporcionando maior destaque aos esforços da empresa na melhoria da relação com investidores, elevando o potencial de valorização dos seus ativos.

Entre os benefícios da adoção das práticas de Governança Corporativa ressalte-se a redução do custo de captação; essa redução é confirmada por pesquisa realizada pela Mckinsey \& Co. e Korn Ferry International (apud IBGC, 2004b), intitulada "Panorama da Governança Corporativa no Brasil". Nessa pesquisa, constata-se que as empresas nacionais, premidas por necessidades de financiamentos e pelos desafios impostos pela competição em nível global, estão reformulando suas práticas de governança corporativa.

Além de contribuir para a redução de custos de capital, a boa governança corporativa agrega valor às sociedades ao proporcionar mecanismos mais efetivos para consolidar negócios competitivos, elevando o nível de confiança entre todos os acionistas.

Outro ponto importante a ser considerado no estudo de Governança Corporativa diz respeito aos denominados Códigos de Melhores Práticas de Governança Corporativa, os quais se referem a um conjunto de normas e diretrizes de governança corporativa. Esses códigos se concentram em problemas de governança advindas da separação entre participação acionária e controle.

Atualmente, dentre os principais Códigos de Melhores Práticas de Governança Corporativa pode-se citar o da OECD, que vem buscando estabelecer um conjunto de princípios essenciais para o desenvolvimento de práticas de boa governança corporativa. Os princípios da OECD (2004a) abrangem os seguintes pontos: I) Direitos dos acionistas; 2) Tratamento igualitário dos acionistas; 3) Posição dos stakeholders (eles precisam ter acesso à informação relevante); 4) Evidenciação e transparência; 5) Responsabilidades do conselho.

No Brasil, especificamente, há o Código Brasileiro das MeIhores Práticas de Governança Corporativa, o qual, de acordo com o IBGC (2004c), tem como objetivo central indicar caminhos para todos os tipos de empresas, visando à melhoria de seu desempenho e à facilidade do acesso ao capital.

Esse código (IBGC, 2004c) possui como linhas principais os seguintes pontos: Transparência; Prestação de contas (accountability); Eqüidade e Responsabilidade Corporativa.

Dentre os principais pontos abordados por esses dois códigos de governança corporativa, destaca-se como sendo o mais importante para fins deste estudo o de Evidenciação e Transparência.

A respeito desse assunto, a OECD (2004a) comenta que a estrutura de governança corporativa deve assegurar divulgação oportuna e precisa de todos os fatos relevantes referentes à empresa, inclusive posição financeira, desempenho, participação acionária e governança.

Para o IBGC (2004c):

O código exige que executivo principal (CEO) e a diretoria satisfaçam às diferentes necessidades de informação dos proprietários, do conselho de administração, da auditoria independente, do conselho fiscal, das partes interessadas (stakeholders) e do público em geral.

Verifica-se, assim, que evidenciação e transparência consubstanciam-se em um dos principais pilares da governança corporativa, de grande destaque em todas as reflexões sobre o assunto e também presente na maioria dos códigos existentes na atualidade.

A ênfase deste artigo é atribuída à governança corporativa em sua interatividade com a contabilidade, no que se refere à prestação de contas e transparência, sendo a divulgação de informações contábeis um instrumento para que se faça cumprir esses dois quesitos. A divulgação contábil consiste em importante ferramenta para redução da assimetria informacional, presente no mercado de capitais e apontada como uma das principais causas das diferenças entre os custos de capital e o valor da empresa.

Estudos empíricos recentes apontam para a avaliação positiva por parte do mercado em relação às empresas que adotam maior nível de transparência, sendo citados: menor custo de capital (BOTOSAN, 1997), menor custo de endividamento (SENGUPTA, 1998) e menor spread (WELKER, 1995). Bushman e Smith (200 I) encontram evidências que a divulgação influencia positivamente a governança corporativa, reduzindo os problemas de agência entre acionistas e administradores. 


\section{MERCADO DE CAPITAIS}

Pode-se entender o mercado financeiro como um conjunto de instituições e instrumentos financeiros destinados a possibilitar a transferência de recursos dos ofertadores para os tomadores, criando condições de liquidez no mercado.

De acordo com Andrezo e Lima (1999, p. 3), o mercado financeiro pode ser basicamente dividido em duas categorias:

- Mercado de Crédito: composto por instituições e instrumentos financeiros destinados a possibilitar operações de curto ou médio prazo.

- Mercado de Capitais: composto por instituições e instrumentos financeiros destinados a possibilitar operações de médio ou longo prazo.

As operações realizadas em Bolsa de Valores são o meIhor exemplo de operações compreendidas por essa última categoria. Assim, nela está inserido o mercado acionário.

Quanto ao desempenho dos mercados de capitais, existem indicadores que tentam demonstrá-lo, dentre os quais se têm os índices. Esses indicadores representam o comportamento dos preços das ações de determinado setor da economia e do comportamento geral das ações no mercado à vista.

De acordo com Assaf (2001, p. 229), os índices de Bolsa de Valores são valores que medem o desempenho médio de preços de supostas carteiras de ações, refletindo o comportamento do mercado em determinado intervalo de tempo.

Brito (1989, p. 137) comenta que os índices do mercado à vista de ações são utilizados como:

I indicadores gerais de tendência do mercado;

II instrumentos de suporte ao processo de administração de investimentos; $\mathrm{e}$

III instrumentos de negociação explícita em mercados futuros.

Assim, os índices do mercado acionário são bastante úteis, uma vez que, ao refletir o comportamento dos investimentos em ações, reflete as tendências gerais da economia.
Dentre os principais indicadores existentes no Brasil, têm-se, dentre outros, o lbovespa e o IBX. Conforme a Bovespa (2004),

o Índice Bovespa é o mais importante indicador do desempenho médio das cotações do mercado de ações brasileiro. Sua relevância advém do fato de o Ibovespa retratar o comportamento dos principais papéis negociados na Bovespa [...].

De acordo com a Bovespa (2004), "a finalidade básica do Ibovespa é a de servir como indicador médio do comportamento do mercado". Contudo, uma das principais críticas a esse índice é a sua excessiva concentração em poucas ações.

No presente estudo, analisa-se a cotação das ações, as quais oferecem resultados ao investidor baseados no seu comportamento de mercado. Assim, o investimento em ações envolve a aceitação de certo grau de risco com relação às oscilações de suas cotações de mercado, entre outros.

De acordo com Assaf Neto (200 I, p. 2I 2), podem ser identificados dois grandes tipos de risco no investimento em ações: risco da empresa captadora de recursos e risco do mercado.

O risco da empresa refere-se àqueles associados à própria atividade da empresa, às características do mercado em que ela opera e também à capacidade em liquidar seus compromissos financeiros assumidos.

Quanto ao risco de mercado, Assaf Neto (200l, p. 213) comenta que:

É identificado pela variabilidade dos retornos de um título em relação ao seu valor médio, denotando menor confiança ao investidor quanto maior for essa variância. Investimentos com retornos mais centrados em seu ponto médio são capazes de oferecer uma melhor aproximação do desempenho esperado futuro.

Assim, quanto maior for a variância de uma ação, maior será seu risco.

\section{NORMAS BRASILEIRAS SOBRE EVIDENCIAÇÃO}

No quadro I $\bullet$, relacionam-se as informações divulgadas com as normas vigentes, leis, instruções, pareceres de orientação e outros. Analisam-se, também, as informações consideradas importantes, mas ainda em caráter voluntário, ou seja, não obrigatórias legalmente.

\section{ESTUDO EMPÍRICO}

Selecionaram-se as companhias abertas que compõem o Índice Bovespa (Ibovespa), por possuírem ações com presença na maioria dos pregões.

Do total das 45 empresas que compõem o Ibovespa (na data da presente pesquisa), excluiram-se as 3 instituições financeiras por possuírem características operacionais muito diferentes das demais, considerando, portanto, 42 companhias. A base de dados desse trabalho refere-se às informações divulgadas pelas 42 empresas selecionadas em seus relatórios anuais do ano de 2002, publicados em 2003, e a cotação das suas ações.

Em relação às informações contábeis, após análise da 


\begin{tabular}{|c|c|}
\hline Informações & Normatizações \\
\hline \multicolumn{2}{|l|}{ Relatório da Administração } \\
\hline Aquisição de debêntures de sua própria emissão & art. 55 da Lei $n^{\circ} 6.404 / 76$ \\
\hline Comentários sobre a conjuntura econômica & Pareceres de Orientação CVM ns 15/87;17/89; $18 / 90$ \\
\hline Descrição dos negócios, produtos e serviços & Pareceres de Orientação CVM ns 15/87;17/89; 18/90 \\
\hline Direitos dos acionistas e dados de mercado & Pareceres de Orientação CVM ns 15/87;17/89; 18/90 \\
\hline Distribuição de dividendos & art. 118 da Lei $n^{\circ}$ 6.404/76 \\
\hline Investimentos & Pareceres de Orientação CVM nº 15/87;17/89; 18/90 \\
\hline Investimentos em coligadas e controladas & Pareceres de Orientação CVM nº 15/87;17/89; 18/90 \\
\hline Negócios sociais e principais fatos administrativos & art. 133 da Lei n 6.404/76 \\
\hline Novos produtos e serviços & Pareceres de Orientação CVM nºs 15/87;17/89; 18/90 \\
\hline Participação dos auditores independentes em consultorias & Instrução CVM n 381/03 \\
\hline Perspectivas e planos para o exercício e os futuros & Pareceres de Orientação CVM nºs 15/87;17/89; 18/90 \\
\hline Pesquisa e desenvolvimento & Pareceres de Orientação CVM ns 15/87;17/89; 18/90 \\
\hline Política de reinvestimento de lucros & art. 118 da Lei $n^{\circ}$ 6.404/76 \\
\hline Proteção ao meio-ambiente & Pareceres de Orientação CVM nº 15/87;17/89; 18/90 \\
\hline Recursos humanos & Pareceres de Orientação CVM nºs 15/87;17/89; 18/90 \\
\hline Reformulações administrativas & Pareceres de Orientação CVM nº 15/87;17/89; 18/90 \\
\hline \multicolumn{2}{|l|}{ Notas Explicativas } \\
\hline Ações em tesouraria & Instruções CVM n’s 10/80 e 390/03 \\
\hline Ajustes de exercícios anteriores & $\begin{array}{l}\text { art. } 176 \text { da Lei n 6.404/76, Ofício-Circular CVM/PTE n³09/86, } \\
\text { Nota Explicativa n 59/86 e PO CVM n¹8/90 }\end{array}$ \\
\hline Arrendamento mercantil - arrendatária & PO CVM n' $15 / 87$ \\
\hline Ativo diferido & PO CVM n' $18 / 90$ \\
\hline Benefícios a empregados & Deliberação CVM n 371/00 \\
\hline Capacidade ociosa & $\mathrm{PO} C V M n^{\circ} 24 / 92$ \\
\hline Capital social & art. 176 da Lei $n^{\circ}$ 6.404/76 e PO CVM n 4/79 \\
\hline Capital social autorizado & Nota Explicativa $n^{\circ} 59 / 86$ \\
\hline Continuidade normal dos negócios & $\mathrm{PO} C V M n^{\circ} 21 / 90$ \\
\hline Créditos Eletrobrás & Deliberação CVM n 70/89 \\
\hline Critérios de avaliação & art. 176 da Lei $n^{\circ}$ 6.404/76 \\
\hline Debêntures & $\mathrm{PO} C V M n^{\circ} 21 / 90$ \\
\hline Demonstrações consolidadas & art. 275 da Lei n 6.404/76 e Instrução CVM n 247/96 \\
\hline Dividendo por ação & art. 186 da Lei n 6.404/76 e Instrução CVM n 59/86 \\
\hline Dividendos & PO CVM n's 15/87, 17/89, 18/90 e 21/90 \\
\hline Empreendimentos em fase de implantação & PO CVM n's $17 / 89$ e $18 / 90$ \\
\hline Equivalência patrimonial & art. 247 da Lei n 6.404/76 e Instrução CVM n $247 / 96$ \\
\hline Eventos subseqüentes & art. 176 da Lei n 6.404/76 \\
\hline Imposto de renda & Deliberação CVM n² 273/98 e Instrução CVM n 371/02 \\
\hline Imposto de renda na fonte sobre lucro líquido & PO CVM n' 18/90 \\
\hline Instrumentos financeiros & Instrução CVM nº 235/95 \\
\hline Mudanças de critérios contábeis & art. 177 da Lei n 6.404/76 \\
\hline Obrigações de longo prazo & art. 176 da Lei $n^{\circ} 6.404 / 76$ e PO CVM n 4/79 \\
\hline Ônus, garantias e responsabilidades eventuais e contingentes & art. 176 da Lei n 6.404/76 e Nota Explicativa n 59/86 \\
\hline Opções de compra de ações & art. 176 da Lei $n^{\circ} 6.404 / 76$ \\
\hline Programa de desestatização & $\mathrm{PO} C V M n^{\circ} 24 / 92$ \\
\hline Provisão para devedores duvidosos & PO CVM n² 21/90 \\
\hline
\end{tabular}


(continuação)

\begin{tabular}{|c|c|}
\hline Informações & Normatizações \\
\hline Provisão para imposto de renda e incentivos fiscais & Ofício-Circular CVM/PTEnº 309/86 \\
\hline Reavaliação & $\begin{array}{l}\text { art. } 176 \text { da Lei } n^{\circ} 6.404 / 76 \text {, Deliberação CVM n } 27 / 86 \text { e Nota } \\
\text { Explicativa } n^{\circ} 59 / 86\end{array}$ \\
\hline Receitas e despesas financeiras & Ofícios-Circulares CVM/PTE ns 578/85 e 309/86 \\
\hline Remuneração dos administradores & Parecer de Orientação CVM n 4/79 \\
\hline Reserva de lucros a realizar & PO CVM n² 24/92 \\
\hline Reservas - detalhamento & Instrução CVM n 59/86 \\
\hline Retenção de lucros & Nota Explicativa n 59/86 e PO CVM n 18/90 \\
\hline Seguros & PO CVM n $15 / 87$ \\
\hline Transações entre partes relacionadas & Deliberação CVM n² 26/86 e PO CVM ns $17 / 89$ e 18/90 \\
\hline Vendas ou serviços a realizar & $\mathrm{PO}$ CVM n² 21/90 \\
\hline \multicolumn{2}{|l|}{ Demonstrações Complementares } \\
\hline \multicolumn{2}{|l|}{ Balanço Social } \\
\hline Demonstração do Fluxo de Caixa & PO CVM n² 24/92 \\
\hline Demonstração do Valor Adicionado & $\mathrm{PO}$ CVM n² 24/92 \\
\hline Demonstrações em Correção Monetária Integral & $\mathrm{PO}$ CVM n² 24/92 \\
\hline Informações Ambientais & \\
\hline
\end{tabular}

Quadro 1 || Informações a serem divulgadas e respectivas normatizações

legislação vigente, Lei no 6.404/76 e CVM, apresentada anteriormente, conclui-se que os itens obrigatórios de divulgação totalizam 173.

As informações publicadas espontaneamente, denominadas demonstrações complementares, perfazem um total de 6.

Utilizou-se a cotação média diária das ações, no período compreendido entre 02/01/2002 a 30/04/2003, para o cálculo da volatilidade, obtida através da Economática, cujo software disponibiliza séries históricas de preços de ativos financeiros, indexadores e eventos de ações.

\subsection{Testes Estatísticos}

Foram utilizadas para a realização desse estudo:

a) Análise de Cluster: trata-se de uma técnica multivariada que permite segregar elementos em grupos homogêneos internamente e heterogêneos entre si.

b) Análise de Variância (ANOVA): teste estatístico cujo objetivo é analisar diferenças entre médias aritméticas, utilizado para saber se há diferenças entre os diversos grupos identificados pela análise de cluster.

c) Teste de Kolmogorov-Smirnov: analisar se a amostra segue a distribuição normal.

d) Teste de Homogeneidade de Variâncias de Levene: verifica se a variância dentro de cada população é igual para todas as populações (homocedasticidade).

e) Teste de Tukey HSD: método que identifica quais grupos, dentre os comparados (ex: grupo I versus grupo 2 e 3), têm diferenças significativas.

f) Teste de Kruskal-Wallis: teste não-paramétrico destinado a verificar se $K$ amostras $(k>2)$ independentes provêm de populações com medianas iguais.
Tem as mesmas propriedades de eficácia em relação ao teste $F$ ANOVA de fator único. Desse modo, o teste de Kruskal-Wallis é uma alternativa não-paramétrica à Análise de Variância.

Os testes estatísticos foram realizados com a utilização do software estatístico SPSS.

Quanto aos critérios estatísticos utilizados nesse estudo, adota-se para a interpretação dos resultados o nível de significância ( $p$-value) de $5 \%$, ou seja, $\alpha=0,5$. Desse modo, se o $p$-value (nível de significância) calculado for menor que o nível de significância escolhido $\alpha$, a hipótese nula é rejeitada.

\subsection{Análise do Nível de Evidenciação 6.2.1 Informações obrigatórias}

Para o cálculo do nível de evidenciação das informações obrigatórias utiliza-se o total das informações obrigatórias identificadas para cada empresa componente da amostra. Esses dados correspondem aos itens constantes no Relatório da Administração e Notas Explicativas.

O nível de evidenciação das informações obrigatórias é calculado dividindo-se o total de informações divulgadas pela empresa pelo total de informações que a empresa deveria ter divulgado. Esse total refere-se ao total de informações divulgadas mais as informações não divulgadas e que deveriam ter sido reportadas pela empresa.

Para exemplo do cálculo, tem-se a seguir: a Cia. de Bebidas das Américas - Ambev - apresenta um total de 80 informações divulgadas no Relatório da Administração e nas Notas Explicativas e apresenta um total de 33 informações não divulgadas, as quais deveriam ter sido divulgadas, no Relatório da Administração e nas Notas Explicativas. 
Assim, o nível de evidenciação de informações obrigatórias da Ambev é:

$$
\text { Ambev }=80 /(80+33)=80 / 113=70,8 \%
$$

No cálculo do nível de evidenciação, a empresa não é prejudicada por não ter a obrigação de divulgar determinada informação, ou seja, somente são consideradas as informações cabíveis de publicação por parte da empresa.

Os resultados obtidos, nessa análise, são apresentados a seguir na tabela 10 .

Após a análise do nível de evidenciação das informações obrigatórias, observe-se que nenhuma empresa divulgou $100 \%$ das informações exigidas e aplicáveis ao seu caso.

\subsubsection{Demonstrações Complementares}

O nível de evidenciação das demonstrações complementares refere-se àquelas demonstrações cujas divulgações são incentivadas e são compostas por: Demonstração do Fluxo de Caixa, Demonstração do Valor Adicionado, Balanço Social, Informações Ambientais e Demonstrações em Correção Monetária Integral.

Para as Demonstrações em Correção Monetária Integral, considera-se, como divulgada pela empresa, a apresentação, no mínimo, do Balanço Patrimonial e da Demonstração de Resultado. Já para as Informações Ambientais, é considerada, como divulgada pela empresa, a apresentação de, pelo menos, 6 itens, cujo valor representa a média de informações publicadas pelas empresas. Outro ponto considerado na análise é se a Demonstração do Fluxo de Caixa foi auditada ou não.

Assim, o nível de evidenciação é calculado dividindo-se o total de demonstrações complementares divulgadas pela empresa por 6 (total de demonstrações complementares a serem divulgadas).

Por exemplo: a Cia. Vale do Rio Doce apresenta todas as demonstrações complementares, ou seja, a Cia. divulga a Demonstração do Fluxo de Caixa auditada, a Demonstração do Valor Adicionado, o Balanço Social, Informações Ambientais e Demonstrações em Correção Monetária Integral.

Assim, o nível de evidenciação das demonstrações complementares da Cia. Vale do Rio Doce é: Cia. Vale do

\section{Rio Doce $=\mathbf{6 / 6}=100 \%$.}

Os resultados obtidos, nessa análise, são apresentados na tabela 20.

Observa-se após a análise do nível de evidenciação das demonstrações complementares, a existência de empresas que divulgaram todas essas demonstrações, Sabesp e Vale do Rio Doce, enquanto outras não divulgaram qualquer demonstração, como a Telesp e outras.

Um fato muito interessante que, pode ser constatado, é que das 42 empresas analisadas 29 (69\% da amostra) publicaram pelo menos $50 \%$ das demonstrações complementares, enquanto apenas 5 das 42 não divulgaram qualquer demonstração. De onde se conclui que um número significativo de empresas analisadas divulga essas demonstrações.

\subsection{Análise de Cluster}

Para a realização da análise de cluster fez-se necessário calcular o percentual de divulgação de cada nota do Relatório da Administração e Notas Explicativas. Esse percentual é determinado somando-se o total de itens evidenciados.

Para as demonstrações complementares, considera-se apenas divulgada ou não a demonstração, sendo desnecessário o cálculo do percentual de divulgação.

Após o cálculo da porcentagem de divulgação, é estabelecido um critério para atribuição de notas, como se demonstra na tabela $3 \boldsymbol{\theta}$.

Após a atribuição das notas, foi efetuada a análise de cluster. Observou-se a formação de 4 grupos, sendo o grupo 4 excluído da análise por conter apenas 2 empresas (Bradespar e NET). Os grupos I, 2 e 3 foram analisados e são formados pelas empresas relacionadas no quadro $2 \boldsymbol{\theta}$.

Após a formação dos grupos com características diferentes em termos de evidenciação, executam-se testes estatísticos para se verificar se os grupos apresentam níveis diferentes de evidenciação.

\subsection{Análise dos Resultados \\ 6.4.1 Análise do Nivel de Evidenciação: Informações obrigatórias e demonstrações complementares}

Os testes estatísticos realizados buscam verificar se os percentuais médios de divulgação apresentados pelos três grupos diferem entre si significativamente.

Quanto ao teste ANOVA, os seus pressupostos básicos de normalidade e homocedasticidade foram verificados, assim o teste pode ser utilizado de modo seguro. Já o teste de Kruskal-Wallis não requer o atendimento de nenhum pressuposto básico.

Os seguintes resultados foram obtidos, quando da análise do nível médio de evidenciação indicados na tabela $4 \bullet$.

Para as informações obrigatórias, pode-se verificar que tanto pelo teste paramétrico (ANOVA) quanto pelo teste não-paramétrico, o nível de significância ( $p$-value) calculado é maior que nível de significância ( $p$-value) adotado de $5 \%$, ou seja, $\alpha=0,05$. Dessa forma, a hipótese nula $\left(H_{0}\right)$ não pode ser rejeitada, ou seja, não se verificou a existência de diferenças significativas entre os grupos quanto aos níveis médios de evidenciação das informações obrigatórias, com um nível de significância de 5\%.

Para as demonstrações complementares, pode-se verificar que, tanto pelo teste paramétrico (ANOVA) quanto pelo teste não-paramétrico, o nível de significância ( $p$-value) calculado é menor que o nível de significância ( $p$-value) adotado de $5 \%$, ou seja, $\alpha=0,05$. Dessa forma, a hipótese nula $\left(H_{0}\right)$ é rejeitada, ou seja, pelo menos um grupo difere com relação ao nível médio de evidenciação das demonstrações complementares. Desse modo, pode-se concluir que existem diferenças significativas entre os níveis médios de evidenciação das demonstrações complementares dos três grupos, com um nível de significância de 5\%.

Todavia, os resultados apresentados na análise do nível de evidenciação das demonstrações complementares 
Tabela 1 Evidenciação das Informações Obrigatórias

\begin{tabular}{|c|c|c|c|}
\hline \multicolumn{4}{|c|}{ Carteira Teórica do Ibovesp a - 1º Quadrimestre de 2003} \\
\hline $\mathbf{N}^{\circ}$ & Empresas Analisadas & Ação & $\begin{array}{l}\text { Nível de Evidenciação } \\
\text { (Informações Obrigatórias) }\end{array}$ \\
\hline 1 & Brasil Telecom & PN N1 & $83,5 \%$ \\
\hline 2 & Brasil Telecom Part. & PN N1 & $82,9 \%$ \\
\hline 3 & Light & ON & $82,3 \%$ \\
\hline 4 & Petrobras & PN & $82,2 \%$ \\
\hline 5 & VCP & PN N1 & $82,2 \%$ \\
\hline 6 & Cemig & PN N1 & $82,1 \%$ \\
\hline 7 & Acesita & PN & $81,5 \%$ \\
\hline 8 & Embraer & PN & $81,5 \%$ \\
\hline 9 & Telesp Celular Part. & PN & $80,7 \%$ \\
\hline 10 & Vale do Rio Doce & PNA & $79,0 \%$ \\
\hline 11 & Telesp & PN & $78,9 \%$ \\
\hline 12 & Siderúrgica Nacional & ON & $78,8 \%$ \\
\hline 13 & Usiminas & PNA & $78,8 \%$ \\
\hline 14 & Gerdau & PN N1 & $77,3 \%$ \\
\hline 15 & CRT Celular & PNA & $77,2 \%$ \\
\hline 16 & Telemar & PN & $76,6 \%$ \\
\hline 17 & Tele Leste Celular & PN & $75,9 \%$ \\
\hline 18 & Embratel Part. & PN & $75,6 \%$ \\
\hline 19 & Sabesp & ON NM & $74,7 \%$ \\
\hline 20 & Cesp & PN & $74,6 \%$ \\
\hline 21 & Copel & PNB & $74,4 \%$ \\
\hline 22 & Eletropaulo & PN & $74,2 \%$ \\
\hline 23 & Siderúrgica Tubarão & PN & $74,1 \%$ \\
\hline 24 & Celesc & PNB N2 & $72,5 \%$ \\
\hline 25 & Klabin & PN N1 & $72,5 \%$ \\
\hline 26 & Telemar NL & PNA & $72,5 \%$ \\
\hline 27 & Tele Celular Sul & PN & $72,4 \%$ \\
\hline 28 & Braskem & PNA & $72,0 \%$ \\
\hline 29 & Telemig Part. & PN & $71,6 \%$ \\
\hline 30 & Ambev & PN & $70,8 \%$ \\
\hline 31 & Tractebel & ON & $70,3 \%$ \\
\hline 32 & Net & PN N2 & $69,6 \%$ \\
\hline 33 & Souza Cruz & ON & $69,2 \%$ \\
\hline 34 & Eletrobrás & PNB & $69,0 \%$ \\
\hline 35 & Ipiranga Pet. & PN & $68,3 \%$ \\
\hline 36 & Aracruz & PNB N1 & $67,3 \%$ \\
\hline 37 & Tele Centro Oeste & PN & $66,1 \%$ \\
\hline 38 & Comgás & PNA & $65,9 \%$ \\
\hline 39 & Itausa & PN N1 & $64,9 \%$ \\
\hline 40 & Transmissão Paulista & PN N1 & $64,8 \%$ \\
\hline 41 & Bradespar & PN N1 & $60,9 \%$ \\
\hline 42 & Tele Nordeste Celular & PN & $57,9 \%$ \\
\hline
\end{tabular}


Tabela 2 || Evidenciação das Demonstrações Complementares

\begin{tabular}{|c|c|c|c|}
\hline \multicolumn{4}{|c|}{ Carteira Teórica do Ibovespa - $1^{\circ}$ Quadrimestre de 2003} \\
\hline $\mathbf{N}^{\circ}$ & Empresas Analisadas & Ação & $\begin{array}{c}\text { Nível de Evidenciação } \\
\text { (Demonstrações Complementares) \% }\end{array}$ \\
\hline 1 & Sabesp & ON NM & 100 \\
\hline 2 & Vale do Rio Doce & PNA & 100 \\
\hline 3 & Cemig & PN N1 & 83,3 \\
\hline 4 & Cesp & PN & 83,3 \\
\hline 5 & Petrobras & PN & 83,3 \\
\hline 6 & Siderúrgica Tubarão & PN & 83,3 \\
\hline 7 & Transmissão Paulista & PN N1 & 83,3 \\
\hline 8 & Usiminas & PNA & 83,3 \\
\hline 9 & VCP & PN N1 & 83,3 \\
\hline 10 & Aracruz & PNB N1 & 66,7 \\
\hline 11 & Brasil Telecom & PN N1 & 66,7 \\
\hline 12 & Brasil Telecom Part. & PN N1 & 66,7 \\
\hline 13 & Eletropaulo & PN & 66,7 \\
\hline 14 & Embrear & PN & 66,7 \\
\hline 15 & Gerdau & PN N1 & 66,7 \\
\hline 16 & Itausa & PN N1 & 66,7 \\
\hline 17 & Tractebel & ON & 66,7 \\
\hline 18 & Acesita & PN & 50 \\
\hline 19 & Ambev & PN & 50 \\
\hline 20 & Braskem & PNA & 50 \\
\hline 21 & Celesc & PNB N2 & 50 \\
\hline 22 & Comgás & PNA & 50 \\
\hline 23 & Ipiranga Pet. & PN & 50 \\
\hline 24 & Klabin & PN N1 & 50 \\
\hline 25 & Light & ON & 50 \\
\hline 26 & Siderúrgica Nacional & ON & 50 \\
\hline 27 & Telemar & $\mathrm{PN}$ & 50 \\
\hline 28 & Telemar NL & PNA & 50 \\
\hline 29 & Telemig Part. & PN & 50 \\
\hline 30 & Bradespar & PN N1 & 33,3 \\
\hline 31 & Copel & PNB & 33,3 \\
\hline 32 & Eletrobrás & PNB & 33,3 \\
\hline 33 & Net & PN N2 & 33,3 \\
\hline 34 & Souza Cruz & ON & 33,3 \\
\hline 35 & Embratel Part. & PN & 16,7 \\
\hline 36 & Tele Celular Sul & $\mathrm{PN}$ & 16,7 \\
\hline 37 & Telesp Celular Part. & PN & 16,7 \\
\hline 38 & CRT Celular & PNA & 0 \\
\hline 39 & Tele Centro Oeste & PN & 0 \\
\hline 40 & Tele Leste Celular & $\mathrm{PN}$ & 0 \\
\hline 41 & Tele Nordeste Celular & PN & 0 \\
\hline 42 & Telesp & PN & 0 \\
\hline
\end{tabular}


Tabela 3 Notas Atribuídas em Função do Nível de Evidenciação

\begin{tabular}{c|c} 
Nota Atribuída & Porcentagem Divulgada \\
\hline 0 & A informação não tinha que ser divulgada \\
\hline 1 & $0 \%$ a $10 \%$ \\
\hline 2 & $11 \%$ a $20 \%$ \\
\hline 3 & $21 \%$ a $30 \%$ \\
\hline 4 & $31 \%$ a $40 \%$ \\
\hline 5 & $41 \%$ a $50 \%$ \\
\hline 6 & $51 \%$ a $60 \%$ \\
\hline 7 & $61 \%$ a $70 \%$ \\
\hline 8 & $71 \%$ a $80 \%$ \\
\hline 9 & $81 \%$ a $90 \%$ \\
\hline 10 & $91 \%$ a $100 \%$
\end{tabular}

\begin{tabular}{|c|l|r|l|l|l|}
\hline \multicolumn{2}{|l|}{ Grupo 1 } & \multicolumn{2}{|c|}{ Grupo 2 } & \multicolumn{2}{c|}{ Grupo 3 } \\
\hline $\mathbf{N}^{\mathbf{0}}$ & Empresa & $\mathbf{N}^{\circ}$ & Empresa & $\mathbf{N}^{\circ}$ & Empresa \\
\hline 1 & Ambev & 4 & Comgás & 20 & Eletrobrás \\
\hline 9 & CST & 23 & Trans. Paulista & 38 & Telemig Part. \\
\hline 13 & VCP & 5 & Sabesp & 30 & CRT Part. \\
\hline 8 & Vale do Rio Doce & 19 & Cesp & 41 & Tele Leste Celular \\
\hline 12 & Aracruz & 6 & Acesita & 33 & Tele Centroeste Cel. \\
\hline 11 & Gerdau & 14 & Klabin & 39 & Telesp \\
\hline 26 & Petrobras & 22 & Light & 32 & Tele Celular Sul \\
\hline 3 & Itausa & 24 & Tractebel & 42 & Tele Nordeste Cel. \\
\hline 29 & Souza Cruz & 7 & Usiminas & 31 & Embratel \\
\hline 10 & CSN & 17 & Cemig & & \\
\hline 36 & Telemar NL & 18 & Copel & & \\
\hline 37 & Telemar & 27 & Ipiranga Pet & & \\
\hline 34 & Brasil Telecom & 40 & Telesp Cel. Part. & & \\
\hline 35 & Brasil Telecom Part. & 21 & Eletropaulo & & \\
\hline 15 & Braskem & 16 & Celesc & & \\
\hline 28 & Embraer & & & 15 & \\
\hline Total de empresas \\
em cada grupo & 16 & & & \\
\hline
\end{tabular}

Quadro 2 Grupos de Empresas Formados

Tabela 4 Resultados dos testes estatísticos de ANOVA e Kruskal-Wallis

\begin{tabular}{c|c|c}
\multirow{2}{*}{ Teste Estatístico } & Informações Obrigatórias & Demonstrações Complementares \\
\cline { 2 - 3 } & $\boldsymbol{p}$-value & $\boldsymbol{p}$-value \\
\hline ANOVA & 0,241 & 0,000 \\
\hline Kruskal-Wallis & 0,311 & 0,000
\end{tabular}


não possibilitam a conclusão de qual ou quais grupos possuem níveis médios de evidenciação significativamente diferentes de outros, tornando-se necessária a aplicação de um teste estatístico de comparações múltiplas. O teste aplicado para esse fim é o de Tukey HSD, apresentado na tabela $5 \mathbf{0}$.

$\mathrm{Na}$ tabela 5, verifica-se que o grupo 3 difere, significativamente, dos grupos I e 2 , enquanto esses dois grupos ( 1 e 2) não diferem entre si.

Assim, confirma-se que o grupo 3 difere significativamente dos demais, possuindo um nível de evidenciação médio das demonstrações complementares menor que os grupos I e 2 , os quais não diferem significativamente.

\subsubsection{Análise da Volatilidade dos Retornos das Ações}

Foi definido como risco de mercado o desvio-padrão dos retornos contínuos das ações, volatilidade.
A volatilidade dos retornos das ações de cada empresa, para o período definido de $1^{\circ} . / 02 / 2002$ - 30/04/2003, é calculada conforme abaixo:

Volatilidade $=D P(R)$, sendo o retorno $(R)$ da ação calculado: $R_{t}=\ln \left(P_{t} / P_{t . t}\right)$, em que: $P_{t}=$ preço no dia $t ; P_{t-1}=$ preço no dia $t-l$ e ln $=$ logaritmo neperiano.

Calculam-se, de acordo com essa metodologia, as volatilidades dos retornos das ações das empresas que compõem a amostra desse estudo. Os resultados são apresentados na tabela $6 \mathbf{0}$.

Pode-se observar que os resultados apresentados pelos três grupos são diferentes. No entanto, para se afirmar, seguramente, que os grupos de empresas apresentam volatilidade média dos retornos diferentes, realizaram-se os mesmos testes estatísticos utilizados para a análise do nível de evidenciação. Quanto ao teste ANOVA, os seus pressupostos básicos de normalidade e homocedasticidade foram verificados, assim o teste pode ser utilizado de modo seguro.

Tabela 5 | Teste de Tukey HSD: Demonstrações Complementares

\begin{tabular}{l|c|c|c}
\multirow{2}{*}{} & \multirow{2}{*}{$\mathbf{N}$} & \multicolumn{2}{|c}{$\alpha=\mathbf{0 , 0 5}$} \\
\cline { 3 - 4 } Grupo 3 & & $\mathbf{1}$ & $\mathbf{2}$ \\
\hline Grupo 2 & 15 & 12,9666 & \\
\hline Grupo 1 & 16 & & 61,1066 \\
\hline Sig. & & 1,000 & 64,5875 \\
\hline
\end{tabular}

Tabela 6 Volatilidade dos Retornos das Ações

\begin{tabular}{l|c|l|l|l|c}
\multicolumn{2}{c|}{ Grupo 1 } & \multicolumn{3}{c}{ Grupo 2 } & \multicolumn{2}{c}{ Grupo 3 } \\
\hline Empresa & Volatilidade & Empresa & Volatilidade & Empresa & Volatilidade \\
\hline Ambev & $1,821 \%$ & Comgás & $2,717 \%$ & Eletrobrás & $2,789 \%$ \\
\hline CST & $2,375 \%$ & Trans. Paulista & $2,293 \%$ & Telemig Part. & $2,744 \%$ \\
\hline VCP & $1,854 \%$ & Sabesp & $2,407 \%$ & CRT Celular & $2,564 \%$ \\
\hline Vale do Rio Doce & $1,717 \%$ & Cesp & $3,012 \%$ & Tele Leste Cel. & $2,733 \%$ \\
\hline Aracruz & $2,071 \%$ & Acesita & $2,355 \%$ & Tele Centroeste Cel. & $3,284 \%$ \\
\hline Gerdau & $2,196 \%$ & Klabin & $2,934 \%$ & Telesp & $1,910 \%$ \\
\hline Petrobras & $2,098 \%$ & Light & $2,973 \%$ & Tele Celular Sul & $2,613 \%$ \\
\hline Itausa & $1,996 \%$ & Tractebel & $2,932 \%$ & Tele Nord. Cel. & $2,640 \%$ \\
\hline Souza Cruz & $1,675 \%$ & Usiminas & $2,621 \%$ & Embratel & $4,677 \%$ \\
\hline CSN & $3,132 \%$ & Cemig & $2,660 \%$ & & \\
\hline Telemar NL & $2,470 \%$ & Copel & $2,836 \%$ & & \\
\hline Telemar & $2,368 \%$ & Ipiranga Pet. & $2,572 \%$ & & \\
\hline Brasil Telecom Part. & $2,518 \%$ & Telesp Cel. ParT. & $3,199 \%$ & & \\
\hline Braskem & $2,790 \%$ & Eletropaulo & $4,025 \%$ & & $\mathbf{2 , 8 8 4 \%}$ \\
\hline Embraer & $2,495 \%$ & Celesc & $2,255 \%$ & & \\
\hline Média & $\mathbf{2 , 2 4 8} \%$ & & $\mathbf{2 , 7 8 6} \%$ & & \\
\hline
\end{tabular}


Tabela 7 Testes da ANOVA e Kruskal-Wallis para a votalidade das ações

\begin{tabular}{c|c}
\multirow{2}{*}{ Teste Estatístico } & Volatilidade dos Retornos das Ações \\
\cline { 2 - 2 } & $\boldsymbol{p}$-value \\
\hline ANOVA & 0,005 \\
\hline Kruskal-Wallis & 0,002
\end{tabular}

Na tabela $7 \mathbf{0}$, são apresentados os resultados obtidos com a análise da volatilidade dos retornos das ações.

Pode-se verificar que tanto pelo teste paramétrico (ANOVA) quanto pelo teste não-paramétrico, o nível de significância ( $p$-value) calculado é menor que o nível de significância (p-value) adotado de 5\%, ou seja, $\alpha=0,05$. Dessa forma, a hipótese nula $\left(H_{0}\right)$ é rejeitada, ou seja, pelo menos um grupo difere com relação à volatilidade média dos retornos das ações.

Dessa forma, pode-se concluir que existem diferenças significativas entre as volatilidades médias dos retornos dos três grupos, com um nível de significância de 5\%.
Contudo, esse resultado não permite concluir qual ou quais grupos possuem volatilidade média dos retornos significativamente diferentes, tornando-se necessária a aplicação do teste estatístico de comparações múltiplas, o teste de Tukey HSD, apresentado na tabela $8 \mathbf{0}$.

Verifica-se que o grupo I difere, significativamente, dos grupos 2 e 3 , enquanto esses dois grupos ( 2 e 3 ) não diferem entre si.

Desse modo, comprova-se que o grupo I difere significativamente dos demais, possuindo uma volatilidade média dos retornos das ações menor que os grupos 2 e 3 , os quais não diferem significativamente.

Tabela 8 - Teste de Tukey HSD: Volatilidade dos Retornos das Ações

\begin{tabular}{l|c|c|c} 
& \multirow{2}{*}{} & $\mathbf{N}$ & \multicolumn{2}{|c}{$\alpha=\mathbf{0 , 0 5}$} \\
\cline { 3 - 4 } Grupo 1 & 16 & $\mathbf{1}$ & $\mathbf{2}$ \\
\hline Grupo 2 & 15 & &, 0224 \\
\hline Grupo 3 & 9 & &, 0288 \\
\hline Sig. & & 1,000 &, 884
\end{tabular}

\section{CONSIDERAÇÕES FINAIS}

Este trabalho investigou a relação existente entre o nível de evidenciação das informações contábeis e a volatilidade do retorno das ações das empresas que compõem o Ibovespa. Para tanto foram analisadas as informações contábeis divulgadas pelas companhias em seus relatórios anuais, a fim de serem identificados os diversos níveis de evidenciação existentes e, também, foram calculadas as volatilidades das ações. Posteriormente, testou-se a hipótese de pesquisa de que a volatilidade do retorno das ações das empresas independe do nível de evidenciação.

Após o desenvolvimento do trabalho, conclui-se que os diferentes níveis de evidenciação influenciam a volatilidade do retorno das ações, resultando na rejeição da hipótese proposta por este estudo, ou seja, as empresas que apresentam um maior nível de evidenciação possuem uma volatilidade média dos retornos de suas ações menor do que as empresas que apresentam um menor nível de evidenciação.

A análise do nível de evidenciação das informações obrigatórias demonstra haver diferenças entre os três grupos, no entanto, essas diferenças são consideradas nãosignificativas pelos testes estatísticos aplicados.
A análise do nível de evidenciação das demonstrações complementares evidencia a existência de diferenças significativas entre os três grupos, sendo que o grupo 3 apresentou o menor nível de evidenciação e os grupos 1 e 2 não apresentaram diferenças significativas entre si.

A análise da volatilidade dos retornos das ações no período definido para o estudo (02.01.2002 a 30.04.2003) mostra que grupos com características diferentes em termos de evidenciação de informações contábeis apresentam volatilidades médias diferentes, tendo o grupo I apresentado a menor volatilidade média dos retornos das ações, sendo significativamente diferente dos grupos 2 e 3 .

Assim, são constatadas diferenças significativas entre os grupos 1 e 3, os quais estão nos extremos, ou seja, entre os grupos detentores do maior e do menor nível médio de evidenciação das demonstrações complementares, respectivamente. Além da característica "evidenciação" analisada, constatou-se que esses mesmos grupos apresentaram volatilidade média dos retornos também diferente, sendo que o grupo I apresenta a menor volatilidade e o grupo 3 a maior. 
O estudo é capaz de revelar que empresas com maior nível de evidenciação, em termos de demonstrações complementares, possuem menor volatilidade do retorno das ações, confirmando, assim, a esperada importância dada pelo mercado a essas demonstrações.

Contudo, dada a amostra intencional e não probabilística, os resultados e conclusões obtidos neste estudo estão limitados ao conjunto de empresas analisadas.
Os resultados alcançados devem ser interpretados como um fator importante para as empresas aumentarem seu nível de transparência e evidenciação de informações e conseqüentemente atenderem a um dos mais importantes pressupostos da Governança Corporativa que é a transparência e a evidenciação, contribuindo para um menor grau de risco e um maior grau de confiabilidade.

\section{Referências Bibliográficas}

ANDREZO, Andréa Fernandes; LIMA, Iran Siqueira. Mercado financeiro: aspectos históricos e conceituais. São Paulo: Pioneira, 1999.

ASSAF NETO, Alexandre. Mercado financeiro. $4^{\mathrm{a}}$ edição. São Paulo: Atlas, 2001.

BNDES - Banco Nacional de Desenvolvimento Econômico e Social. Mais incentivo à adoção de regras de Governança Corporativa e à emissão de debêntures. Notícias. Disponível em: <http://www.bndes.gov.br > Acesso em: 20/01/2004.

BOTOSAN, Christine A.. Disclosure level and the cost of equity capital. The Accounting Review, vol. 72, nº. 3, julho de 1997.

BOVESPA - Bolsa de Valores de São Paulo. Índices. Disponível em: <http://www.bovespa.com.br/Indices/ApresentaçãoP. asp? Indice=Ibovespa $>$. Acesso em: 5/3/2004.

BRASIL. Lei n ${ }^{\circ}$. 6.404, de 15 de dezembro de 1976. Dispõe sobre as sociedades por ações. Publicada no DOU, em 15 de dezembro de 1976. BRITO, Ney Roberto Ottoni de. Índice brasileiro de ações: uma proposta. BRITO, Ney Roberto Ottoni de (org.). Gestão de Investimentos. São Paulo: Atlas, 1989.

BUSHMAN, R.; SMITH, A.. Financial Accounting Information and Corporate Governance. Journal of Accounting and Economics. V.32, p.237-333, 2001.

CVM - Comissão de Valores Mobiliários. Recomendações da CVM sobre governança corporativa. Disponível em: <http://www.cvm.gov. br>. Acesso em: junho de 2002.

ECCLES, Robert G. et al. The ValueReporting revolution: moving beyond the earnings game. PricewaterhouseCoopers. New York: John Wiley \& Sons, Inc., 2001.

IASB - International Accounting Standards Board. Normas internacionais de contabilidade 2001: texto completo de todas as normas internacionais de contabilidade e interpretações SIC existentes em $1^{\circ}$ de janeiro de 2001. São Paulo: IBRACON, 2001.

IBGC - Instituto Brasileiro de Governança Corporativa. Governança corporativa. Disponível em: <http://www.ibgc.org.br>. Acesso em: $12 / 02 / 2004 a$

Governança corporativa no Brasil. Disponível em: <http://www.ibgc.org.br>. Acesso em: 12/02/2004b.

Código brasileiro das melhores práticas de governança corporativa. Disponível em: <http://www.ibgc.org.br $>$. Acesso em:

$12 / 02 / 2004 c$.

IUDÍCIBUS, Sérgio de. Teoria da contabilidade. 6a edição. São Paulo: Atlas, 2000.

LOPES, Alexsandro B. A Relevância da Informação Contábil para o Mercado de Capitais: O Modelo de OHLSON aplicado à BOVESPA. Tese 2001. (Doutorado em Controladoria e Contabilidade). Departamento de Contabilidade da Faculdade de Economia, Administração e Contabilidade da Universidade de São Paulo, São Paulo.

ORGANISATION FOR ECONOMIC CO-OPERATION DEVELOPMENT - OECD. OECD principles of corporate governance. Disponível em: <http://www.oecd.org $>$. Acesso em: 14/02/2004a.

SENGUPTA, Partha. Corporate Disclosure Quality and the Cost of Debt. The Accounting Review. Vol. 74, nº. 4, p.459-474, Oct 1998.

SHLEIFER, A.; VISHNY, R.W.. A survey of corporate governance. Journal of Finance. Vol. 52, p. 737-783, June 1997.

SIFFERT FILHO, Nelson Fontes. Governança corporativa: padrões internacionais e evidências empíricas no Brasil nos anos 90 . Revista do BNDES. Rio de Janeiro. V.5, n.9, p. 123-46, junho de 1998.

THOMSON FINANCIAL. Governança corporativa perpetua boas práticas de gestão e disclosure. RI - Relações com Investidores. Rio de Janeiro, n'. 66, agosto de 2003.

TIROLE, Jean.. Corporate governance. Econometrica. V. 69, №. 1; January, 2001, p. 1-35.

YAMAMOTO, Marina M.. Governança e o valor das empresas. Disponível em: <http://www.bovespa.com.br/Bovespa/RevistaBovespa/88/ Tendencias.shtml>. Acesso em: 15 de maio de 2004.

WELKER, M. Disclosure Policy, Information Asymetry and Liquidity in Equity Markets. Contemporary Accounting Research , 11, Spring p. 801-827, 1995.

\section{NOTA - Endereço dos autores}

Universidade de São Paulo

Faculdade de Economia, Administração e Contabilidade

Departamento de Contabilidade e Atuária
Av. Prof. Luciano Gualberto, 908 - prédio 3 - Cidade Universitária

São Paulo - SP

05.508-900 